\title{
Applying quantile regression to determine the effects of household characteristics on household saving rates in Vietnam
}

\author{
Thanh Xuan Hua \\ Can Tho University, Can Tho, Vietnam and \\ Department of Economics, University of Antwerp, Antwerp, Belgium, and \\ Guido Erreygers \\ Department of Economics, University of Antwerp, Antwerp, Belgium and \\ Centre for Health Policy, University of Melbourne, Melbourne, Australia
}

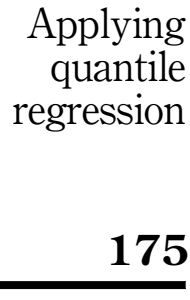

Received 6 June 2019 Revised 23 August 2019 15 October 2019 Accepted 6 November 2019

\begin{abstract}
Purpose - The purpose of this paper is to analyse the determinants of the saving behaviour of Vietnamese households and to explore the possible heterogeneity of household saving propensities.

Design/methodology/approach - The authors estimate the effects of household characteristics on Vietnamese household saving rates by means of a quantile regression approach using the Vietnam Household Living Standard Survey 2010 data set.

Findings - The results suggest that the way household characteristics influence saving rates is different for each quantile of the household saving rate distribution. Household characteristics tend to have stronger effects at lower quantiles. Particularly, the marginal propensity to save of households at low quantiles is higher than those at high quantiles. Analysing rural and urban households separately, the authors find evidence that household and household head characteristics have stronger significant effects for rural than for urban households. Children and elderly members should be treated as part of the household labour force, instead of household dependency, since both of them increase household saving rates.

Originality/value - This research contributes to the literature on Vietnamese household saving behaviours, especially for households living in urban areas.
\end{abstract}

Keywords Vietnam, Quantile regression

Paper type Research paper

\section{Introduction}

The contribution of national saving in general, and household saving in particular, to economic growth of a country has been confirmed in various studies (Aron and Mihaescu, 2014; Deaton and Paxson, 2000). Therefore, understanding household saving behaviour, specifically its determinants, has been the focus of a lot of empirical research. As far as Vietnam is concerned, Minh et al. (2013) studied household saving behaviour by distinguishing four types of saving and by estimating the level of consumption of households. Additionally, Ha et al. (2015) examined the short-term precautionary saving motives of Vietnamese households with positive saving levels, while Sepehri and Akram-Lodhi (2005) analysed the role of both domestic and foreign saving for Vietnam.

(C) Thanh Xuan Hua and Guido Erreygers. Published in Journal of Asian Business and Economic Studies. Published by Emerald Publishing Limited. This article is published under the Creative Commons Attribution (CC BY 4.0) licence. Anyone may reproduce, distribute, translate and create derivative works of this article (for both commercial \& non-commercial purposes), subject to full attribution to the original publication and authors. The full terms of this licence may be seen at http://creativecommons.org/licences/by/4.0/legalcode

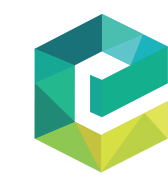

Journal of Asian Business and Economic Studies Vol. 27 No. 2,2020 pp. $175-193$ Emerald Publishing Limited 2515-964X 
JABES

27,2

176

Nevertheless, not all aspects of household saving in Vietnam have been explored fully. It is the main reason for us to investigate the effects of household characteristics on Vietnamese household saving rates. Our aim with this paper is to improve our understanding of the saving behaviour of Vietnamese households.

Determinants of household savings are studied from both macro and microeconomic perspectives. On the one hand, household savings are influenced by economic growth, inflation, unemployment and interest rates in the context of macroeconomics (Aron and Mihaescu, 2014; Loayza et al., 2000). On the other hand, analysing the determinants of household savings based on individual household units allows us to dig deeper into household saving behaviour from a microeconomic perspective (Abdelkhalek et al., 2010; Minh et al., 2013; Pan, 2016; Rehman et al., 2011). In our research we adopt a microeconomic empirical approach.

Following this approach, Klein (1951) used survey data to identify the effects of a range of socioeconomic and demographic variables (i.e. not just household income) on household savings. The effects of these characteristics on household savings were then explained by the relative income hypothesis (Duesenberry, 1949), life cycle theory (Modigliani and Brumberg, 1954) and permanent income hypothesis (Friedman, 1957). The relationship was also the subject of various empirical studies (Akhtar, 1987; Horioka and Wan, 2007; Horioka and Watanabe, 1997; Minh et al., 2013; Nalin, 2013; Schunk, 2009).

According to these studies, household characteristics frequently listed as affecting household saving behaviour include living area, education, marital status and race or ethnicity of the household head, etc. Among them, residence or living area of households is the most commonly considered factor. Results suggest that saving behaviours in rural and urban areas are not homogenous (Bautista and Lamberte, 1990; Burney and Khan, 1992; Qian, 1988). Only a few papers have investigated the saving behaviour in rural areas of Vietnam (Ha et al., 2015; Minh et al., 2013; Newman et al., 2008, 2014). The saving behaviour of urban households in Vietnam still needs to be studied in detail.

The objective of this paper is to reveal the effects of household characteristics on Vietnamese household savings, for the whole country as well as for rural and urban areas separately. A conditional quantile regression approach is applied in order to take into account the heterogeneity of household saving propensities. Our results may contribute to the formulation and implementation of suitable policies with regard to household savings, and therefore to the promotion of economic growth and socioeconomic development in Vietnam.

This paper is structured in six sections. After the introduction, Section 2 briefly reviews the empirical evidence and presents the arguments for our hypotheses concerning the effects of household characteristics on household savings. Section 3 introduces the data set, the variables and the models which are used in the paper. Section 4 reports our empirical findings and discussions. In Section 5, we do a robustness check for the result. The final section provides the conclusion of the paper.

\section{Empirical evidence and hypothesis development}

Some of the most influential views on consumption and saving are now known as the absolute income hypothesis associated to the work of Keynes (1936), the relative income hypothesis formulated by Duesenberry (1949), the life cycle theory developed by Modigliani and Brumberg (1954) and the permanent income hypothesis advanced by Friedman (1957). Informed by these theories, empirical researchers found evidence that consumption and saving decisions are not only determined by current income, but also by household characteristics such as living place, gender, educational level and ethnicity of the household head, and the number of children and elderly household members. We summarise important findings of this literature here below. 


\subsection{Living place of the household (urban/rural)}

Duesenberry (1949, p. 61) highlighted that "farm families have a higher propensity to save than city families", and Friedman (1957) affirmed the heterogeneity of saving behaviour between urban and rural households. Numerous empirical studies have found evidence that there are differences both in the rates and in the levels of savings (Abdelkhalek et al., 2010; Akhtar, 1987; Bebczuk et al., 2015; Nalin, 2013; Qian, 1988).

According to these studies, the heterogeneous saving behaviour between urban and rural households could be explained by the stability of incomes and social benefits. On the one hand, most urban residents are labourers with a fixed income and a fixed retirement age. On the other hand, households in rural areas are often farmers on their own land. Hence, their income is more volatile and less stable due to the risks of climate, the market and management of production. In addition, they also have limitations in reaching healthcare systems and insurance services. Faced with such risks, rural households would have an incentive to create a strong mechanism to smooth their consumption effectively to protect themselves. Thereby, they would have stronger saving motives and a higher saving rate, ceteris paribus:

H1. Rural households have higher saving rates than urban households, after controlling for income and other characteristics.

\subsection{Gender of household head (male/female)}

The gender of the household head is known to be a very common factor affecting household saving behaviour (Abdelkhalek et al., 2010; Gries and Dung, 2014; Minh et al., 2013; Schunk, 2009). In many papers it is found that the saving behaviours of males and females are not homogeneous. It appears that males save less than females, as income and other factors are controlled. The differences in savings between males and females are explained by differences in life span, permanent income component and wealth. Particularly, due to lower ages of retirement (Warren et al., 2001), more unstable incomes (Fisher, 2010; Warren et al., 2001) and more responsibility for bearing children (Abdelkhalek et al., 2010), female household heads tend to have higher saving motives than male. As a result, they would save more than male household heads, ceteris paribus:

H2. Female household heads have higher saving rates than male household heads, after controlling for income and other characteristics.

\subsection{Educational level of household head}

The effect of education on household saving behaviour is complex (Akhtar, 1987; Morisset and Revoredo, 1995). On the one hand, well-educated household heads are wiser when it comes to making choices with regard to current and future expenditure and to choosing effective saving and investment methods. Hence, they can save more (Bersales and Mapa, 2006; Horioka and Watanabe, 1997; Morisset and Revoredo, 1995; Schunk, 2009). On the other hand, higher education also creates a motive for households to spend more, especially for the education of their children (Akhtar, 1987; Bebczuk et al., 2015). As a result, this will restrict their savings. In the case of Vietnam, we expect that households with high educational levels tend to have high consumption rates and therefore low saving rates, ceteris paribus, due to the following reasons. First, according to Morisset and Revoredo (1995), with higher educational levels, people have more chances to secure a good and stable job. Second, with higher educational levels, households more easily find the effective insurance and financial products to protect themselves and their family from unexpected shocks (Akhtar, 1987). Third, the negative effect of education levels on household savings can be explained by the preferences of parents towards their children's education (Aizenman et al., 2015; Akhtar, 1987; Rehman et al., 2011; Bebczuk et al., 2015). Particularly, 
JABES

27,2

178

household heads with higher educational levels are willing to sacrifice all their current savings to the education of their children. We therefore expect that low educational levels would be associated with high saving rates, if other variables are controlled for:

H3. Household heads with higher educational levels have lower saving rates than household heads with lower educational levels, after controlling for income and other characteristics.

\subsection{Ethnicity}

Depending on their culture, language, habits, etc., households with different race or ethnicity could have different consumption and saving behaviours (Banerjee et al., 2010; Borgo, 2019; Charron-Chénier et al., 2016; Friedman, 1957; Klein, 1951). Vietnam is a multi-ethnic country consisting of 54 distinct ethnic groups with their own languages, lifestyle and cultural heritage. We believe that the ethnic background affects household saving behaviour in Vietnam. As the largest ethnic group with over 80 per cent of the total population, the Kinh may have wider social and family networks than other ethnicities. If so, in cases of emergency Kinh households could receive more extensive financial support from the networks of their family, relatives and friends than households from ethnic minorities (Newman et al., 2014). This could reduce their precautionary saving motive and therefore make their saving rate lower than that of ethnic minority households:

H4. Household heads with an ethnic minority background have higher saving rates than Kinh household heads, after controlling for income and other characteristics.

\subsection{Children and elderly household members}

As in the case of education, the influence of children and elderly household members on household saving is complicated. On the one hand, children and elderly members are usually treated as indicators for household dependency (Akhtar, 1987; Burney and Khan, 1992; Curtis et al., 2015; Goldberger, 1973; Kelley, 1980; Khan et al., 1992; Schunk, 2009). Particularly, with more children, households usually spend more on care-taking and education. Additionally, households with more elderly members tend to spend more on health expenditure. As a result, with high dependency, households would spend more and save less of their income. On the other hand, dependency creates more precautionary and bequest saving motives for households (Curtis et al., 2015; Horioka and Watanabe, 1997; Schunk, 2009). Additionally, some elderly members could be treated as part of the labour force of the household (Minh et al., 2013). This may be the case in Vietnam, an agricultural country with a low-middle income level. Regardless of their age, Vietnamese household members are often involved in all economic activities of the household. This could induce households with a lot of members to have relatively high levels of saving:

H5. Children and elderly members have positive effects on the saving rates of Vietnamese households.

\section{The data set, theoretical model and variable measurement}

\subsection{Data set}

In this paper, the data set Vietnam Household Living Standard Survey (VHLSS) 2010 is used. This data set includes 9,399 households. Since the minimum legal age to be a household head in Vietnam is 18 years, household heads below this age are not included in our sample. Due to missing data on some covariates, we end up with a final set of 8,760 households. We take into account the sample weights provided by the survey for all analyses in our paper. 


\subsection{Theoretical model and variable measurements}

To achieve our objectives, the household saving rate (SRATE), defined as the amount of savings divided by income, is used as the dependent variable. According to economic theory and empirical studies, household income is a crucial determinant of household savings. It will be the first independent variable in our model. Next, we add other independent variables including: living area of the household (URBAN), gender of the household head (MALE), age of the household head ( $A G E)$, ethnicity of the household head (KINH_ETH), educational level of the household head (EDU1, EDU2, EDU3), number of children under six years of age in the household (CHILD1), number of children between 6 and 14 years of age in the household (CHILD2), number of elderly members in the household (ELDERLY) and household size (HHSIZE). We measure these variables as follows:

(1) Household income: the actual levels of yearly household income (INCOME) are expressed in VND 1,000, as in the data set. In our regression analysis, we always use the logarithm of this income (lnINCOME).

(2) $U R B A N=1$ if the household lives in an urban area and 0 otherwise.

(3) $M A L E=1$ if the household head is male and 0 otherwise.

(4) $A G E=$ the number of years of age of the household head. According to the life cycle theory (Modigliani and Brumberg, 1954), the relationship between savings and age is non-linear. Therefore, besides the age of the household head, we will also consider its square $(S A G E)$.

(5) $K I N H \_E T H=1$ if the ethnicity of the household head is Kinh and 0 otherwise.

(6) Educational level of the household head: we consider four groups of educational attainment: no degree, primary school, secondary and high school; college degree; university degree; master, $\mathrm{PhD}$ and other higher educational level degree. Taking the last group as the reference category, we define the following three dummy variables:

- $\quad E D U 1=1$ if the household head has no degree, primary school, secondary and high school and $E D U 1=0$ otherwise.

- $E D U 2=1$ if the household head has a college degree and $E D U 2=0$ otherwise.

- $E D U 3=1$ if the household head has a university degree and $E D U 3=0$ otherwise.

(7) $\quad$ CHILD1 = the number of children under six years old in the household. Households with a lot of children in these years of age are expected to have high expenses related to care-taking and raising children.

(8) CHILD2 = the number of children from 6 to 14 years of age in the household. Households with a lot of children in this age bracket are expected to have high expenditures for the schooling of their children.

(9) $E L D E R L Y=$ the number of elderly members, i.e. who are over the age of 70 , in the household. Although the age of retirement is 60 for men and 55 for women, men and women are usually still in good health at these ages. We suppose that men and women over the age of 70 are more frequently confronted with serious health problems. As a result, households with elderly members often have high healthcare expenditures.

(10) $H H S I Z E=$ the number of household members.

Basic descriptive statistics of these variables can be found in Table I. 


\begin{tabular}{llrrrr} 
JABES & Variables & Mean & SD & Min. & Max. \\
\cline { 2 - 5 } 27,2 & SRATE & -0.008 & 0.590 & -26.448 & 0.960 \\
& lnINCOME & 10.854 & 0.809 & 7.235 & 14.658 \\
& KINH_ETH & 0.882 & 0.322 & 0 & 1 \\
& URBAN & 0.313 & 0.464 & 0 & 1 \\
$\mathbf{1 8 0}$ & MALE & 0.752 & 0.432 & 0 & 1 \\
& AGE & 48.242 & 13.824 & 18 & 1 \\
& EDU1 & 0.922 & 0.268 & 0 & 1 \\
& EDU2 & 0.015 & 0.122 & 0 & 1 \\
& EDU3 & 0.058 & 0.233 & 1 & 4 \\
& HHSIZE & 3.865 & 1.516 & 0 & 6 \\
Table I. & CHILD1 & 0.363 & 0.604 & 0 & 3
\end{tabular}

Descriptive statistics Notes: All means and standard deviations are calculated using the sample weights provided in the VHLLS of the variables 2010 survey. The number of observations is 8,760

The full model we investigate in this paper is the following:

$$
\begin{aligned}
& R S A V E_{i}=\alpha+\beta_{1} \ln I N C O M E_{i}+\beta_{2} U R B A N_{i}+\beta_{3} M A L E_{i}+\beta_{4} A G E_{i}+\beta_{5} S A G E_{i} \\
& +\beta_{6} E D U 1_{i}+\beta_{7} E D U 2_{i}+\beta_{8} E D U 3_{i}+\beta_{9} K I N H_{i} \\
& +\beta_{10} C H I L D 1_{i}+\beta_{11} C H I L D 2_{i}+\beta_{12} E L D E R L Y_{i}+\varepsilon_{i} \text {. }
\end{aligned}
$$

We employ two strategies to estimate the coefficients of our model. We begin by applying OLS, but as an alternative approach we also apply conditional quantile regression as proposed by Koenker and Bassett (1978). This approach allows us to take into account the heterogeneity of saving propensities. While OLS regression considers the effect of household characteristics on household savings at the mean, quantile regression considers this relationship at different quantiles (denoted by $q$ ) of the distribution of the saving rate. Therefore, this approach provides a more comprehensive picture about the impact of household characteristics along the conditional distribution of household saving rates. For this reason, quantile regression is increasingly applied in various empirical studies (Martins and Pereira, 2004; Melly, 2005). Our motivations for applying quantile regression as an alternative to OLS are as follows.

First, while the OLS regression approach requires the assumptions of homoscedasticity and normal distribution of the error term, the quantile regression approach can be applied even when these assumptions are violated.

Second, there is evidence of outliers in our data. These outliers would cause the estimators of OLS regression to be biased. Quantile regression gives us robust results even in the presence of outliers (Koenker and Bassett, 1978).

Third, the mean and standard deviation of the saving rate presented in Table I reveal that its distribution is characterised by a large variability. Indeed, as shown in Figure 1, the household saving rate has a skewed distribution. Hence, the mean and standard deviation are not good measures for the location and shape of the whole distribution. As a result, with only one regression, the OLS approach may not be representative.

Fourth, it is well-known that household income is the most crucial determinant of household savings. Nevertheless, Figure 2 shows that there is a lot of heterogeneity in the relation between the household saving rate and the logarithm of income. With only one regression, the OLS approach could provide poor estimators for the determinants of the household saving rate. 


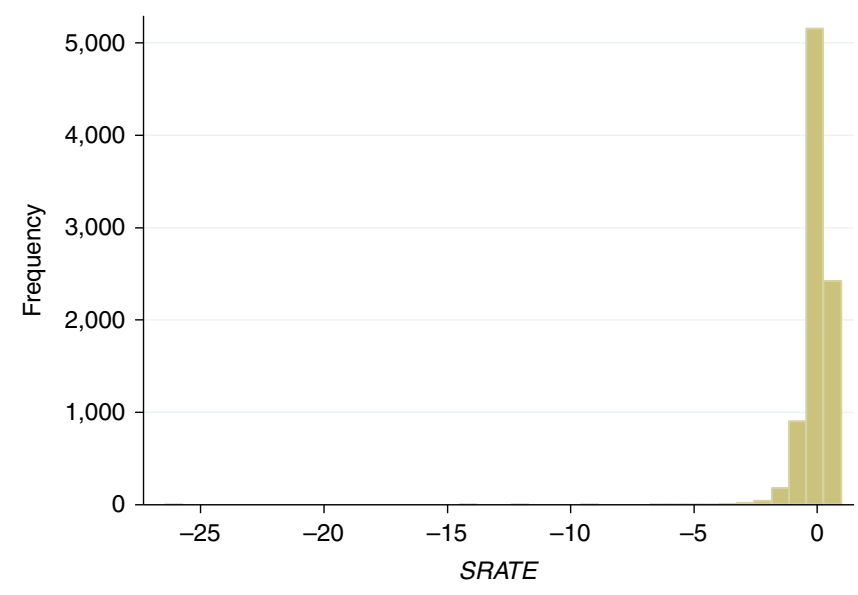

Applying quantile regression

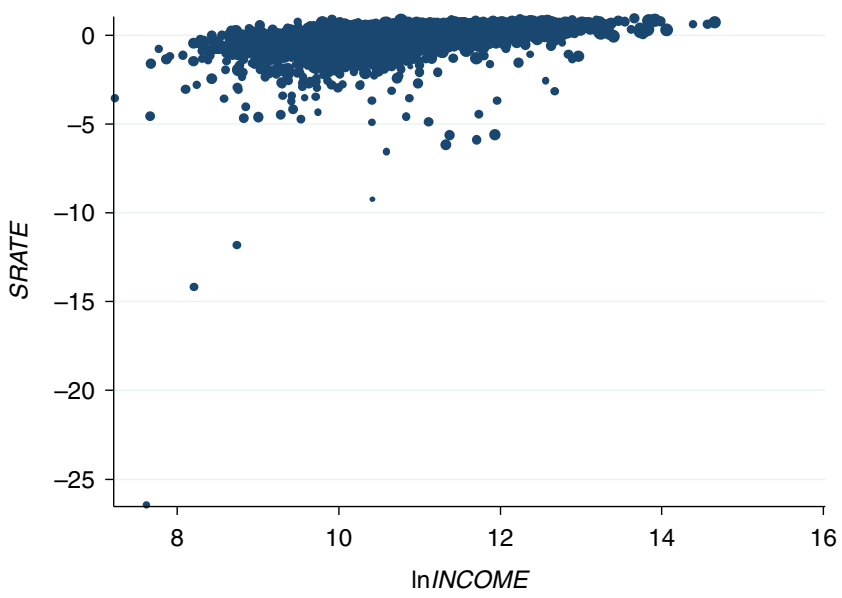

Figure 1.

The frequency graph of household saving rates

Figure 2.

Scatter of household saving rates and household income

In sum, the above analysis indicates that the quantile regression approach may yield better results than the OLS approach. Therefore, we apply quantile regression as an alternative for the OLS approach to observe the effect of household characteristics on the household saving rate along the whole saving distribution. Particularly, we construct nine quantile regressions for the quantiles $q=0.1 ; 0.2 ; \ldots ; 0.9$. We follow Koenker and Bassett (1978) in constructing our quantile regressions. At each quantile $q$, the vector of quantile regression estimators $\beta_{q}$ is determined so that the following objective function is minimised:

$$
Q\left(\beta_{q}\right)=\sum_{i: y_{i}>x_{i}^{\prime} \beta_{q}}^{N} q\left|y_{i}-x_{i}^{\prime} \beta_{q}\right|+\sum_{i: y_{i}<x_{i}^{\prime} \beta_{q}}^{N}(1-q)\left|y_{i}-x_{i}^{\prime} \beta_{q}\right| .
$$

In the next section, we present our empirical findings for the whole country as well as for urban households and rural households separately. 
JABES

27,2

\section{Empirical findings and discussions}

First, we briefly discuss the descriptive statistics concerning the saving rate of Vietnamese households. Second, we present the empirical findings obtained from the OLS and quantile regression approaches.

\subsection{Descriptive statistics on the saving rate}

As shown by the data of Table I, the Vietnamese household saving rate distribution is characterised not only by a low and even negative mean, but also by a large variability as indicated by the high value of the standard deviation[1]. Nevertheless, the aggregate household saving rate defined as the mean of household saving levels divided by the mean of household income levels is 17.45 per cent[2]. This number shows that on the whole, the household sector still has positive savings and therefore contributes positively to the aggregate saving account of Vietnam. As a result, households play an important role in the economic growth and socioeconomic development of Vietnam.

\subsection{Empirical findings and discussions}

In this section, we analyse the effect of household and household head characteristics on the Vietnamese household saving rate in both OLS and quantile regressions. In Table II, we report the results for the whole sample[3]. The OLS regression results are in the column labelled "OLS" and the nine quantile regression results in the columns labelled "Q1" for $q=0.1$; "Q2" for $q=0.2$; etc.

We also use bivariate scatterplots to represent the results obtained from the two regression approaches for the whole sample in Figure 3, for urban households in Figure 4 and for rural households in Figure 5 . We have one bivariate scatterplot for each independent variable. The values of the horizontal axis of each plot indicate the quantiles of the household saving rate distribution. The values on the vertical axis represent the estimated values of the coefficients of the independent variables. Each bivariate plot includes one solid curve which connects the estimated values of the nine quantile regression estimators, one dashed line which presents the OLS estimator of the conditional mean effect, two dotted lines which are the conventional 90 per cent confidence intervals for the OLS estimator, and a shaded grey area which represents the 90 per cent point wise confidence intervals for the quantile regression estimators.

In all three figures, the quantile regression estimators for some covariates, and especially for household income, often deviate significantly from the corresponding OLS regression estimator. This again suggests that for our study, the quantile regression approach is more adequate than the OLS regression approach.

Next, we discuss the effect of the various household characteristics on the household saving rate.

Household income and household size. First, household income appears to be the most important factor affecting household saving rates, as indicated by economic theory. We find that current household income tends to have a positive effect on the saving rates of Vietnamese households. In other words, an increase of household income would lead to an increase of the household saving rate. Our findings support the evidence that current household income not only affects the level of household savings, but also the rate. The OLS regression results seem to be in line with the absolute income hypothesis (Keynes, 1936) and be consistent with the results of empirical studies for other countries, such as Australia (Harris et al., 2002), China (Pan, 2016; Qian, 1988) and Poland (Szopinski, 2017).

Another interesting finding is that, as reported in Table II, the marginal propensity to save (MPS) is higher in low quantiles than in high quantiles. In other words, households 
Table II.

The effects of household and household head characteristics on Vietnamese household saving rates in 2010 
JABES

27,2

184
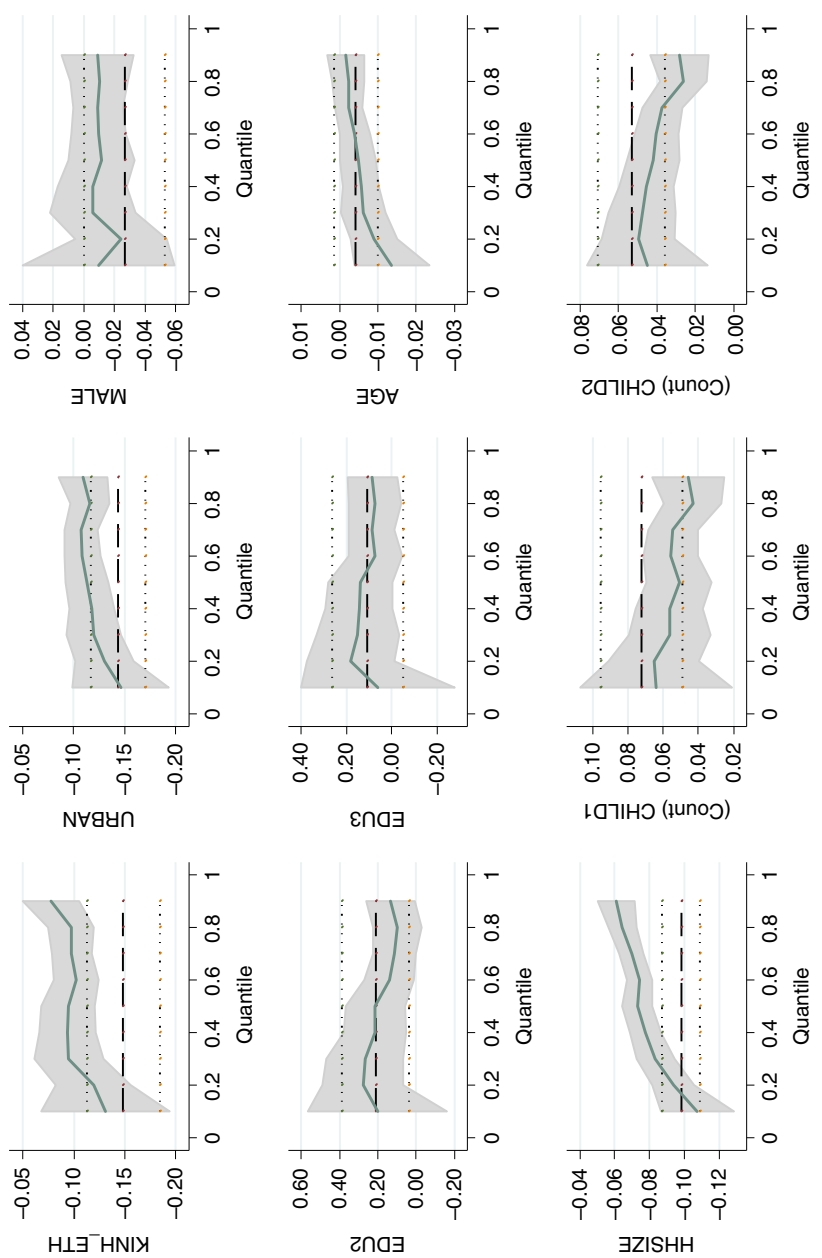

Figure 3.

Ordinary least squares regression and quantile regression estimates for Vietnamese household saving rate
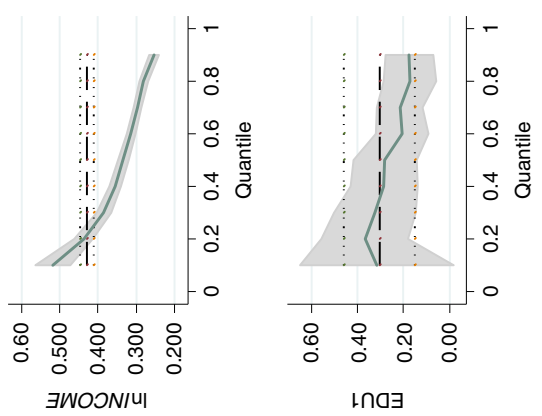

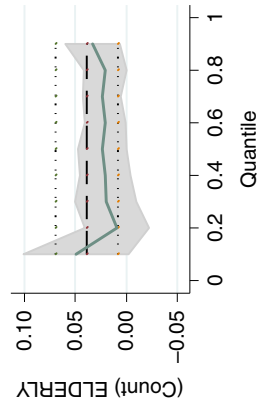




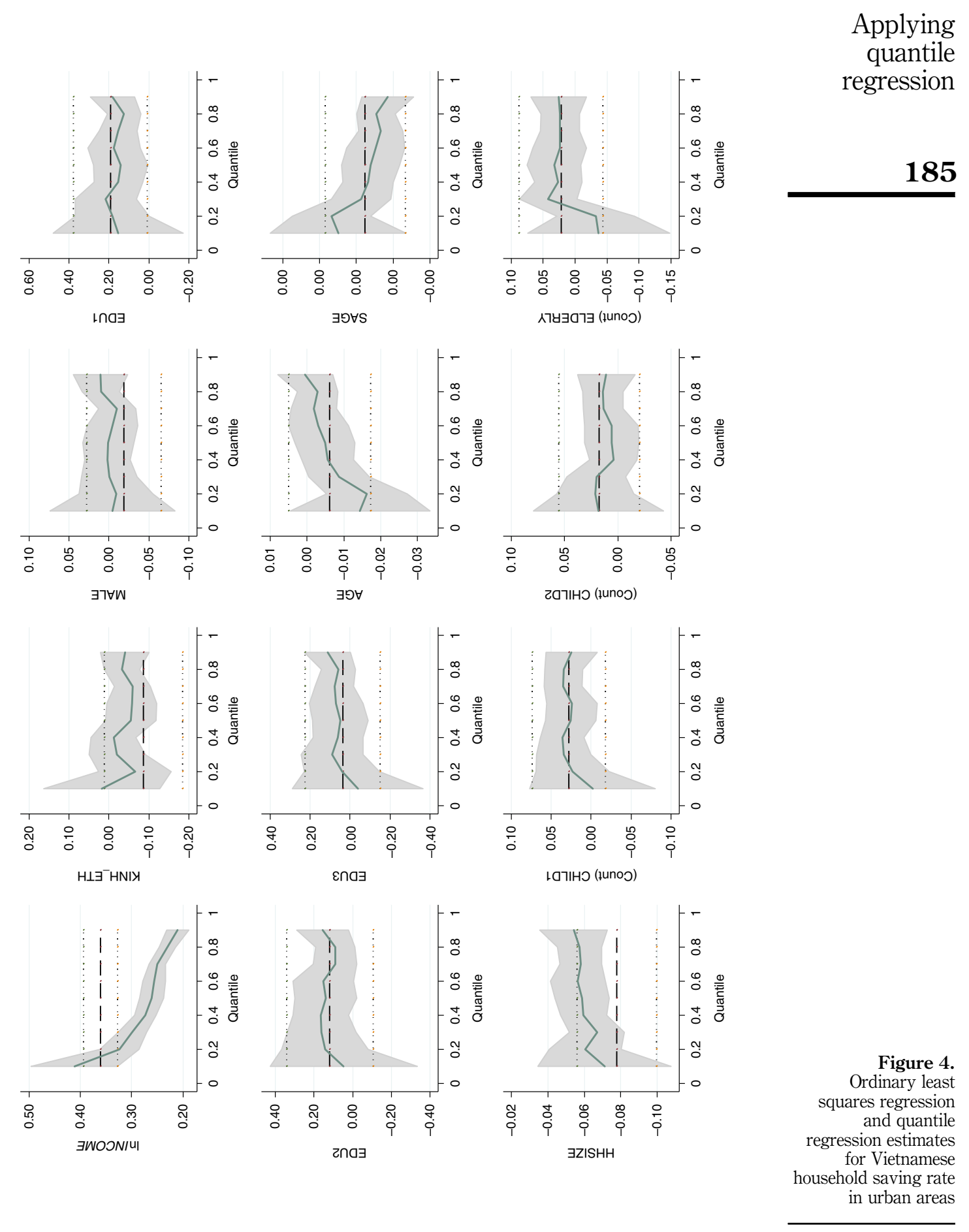


JABES

27,2

186
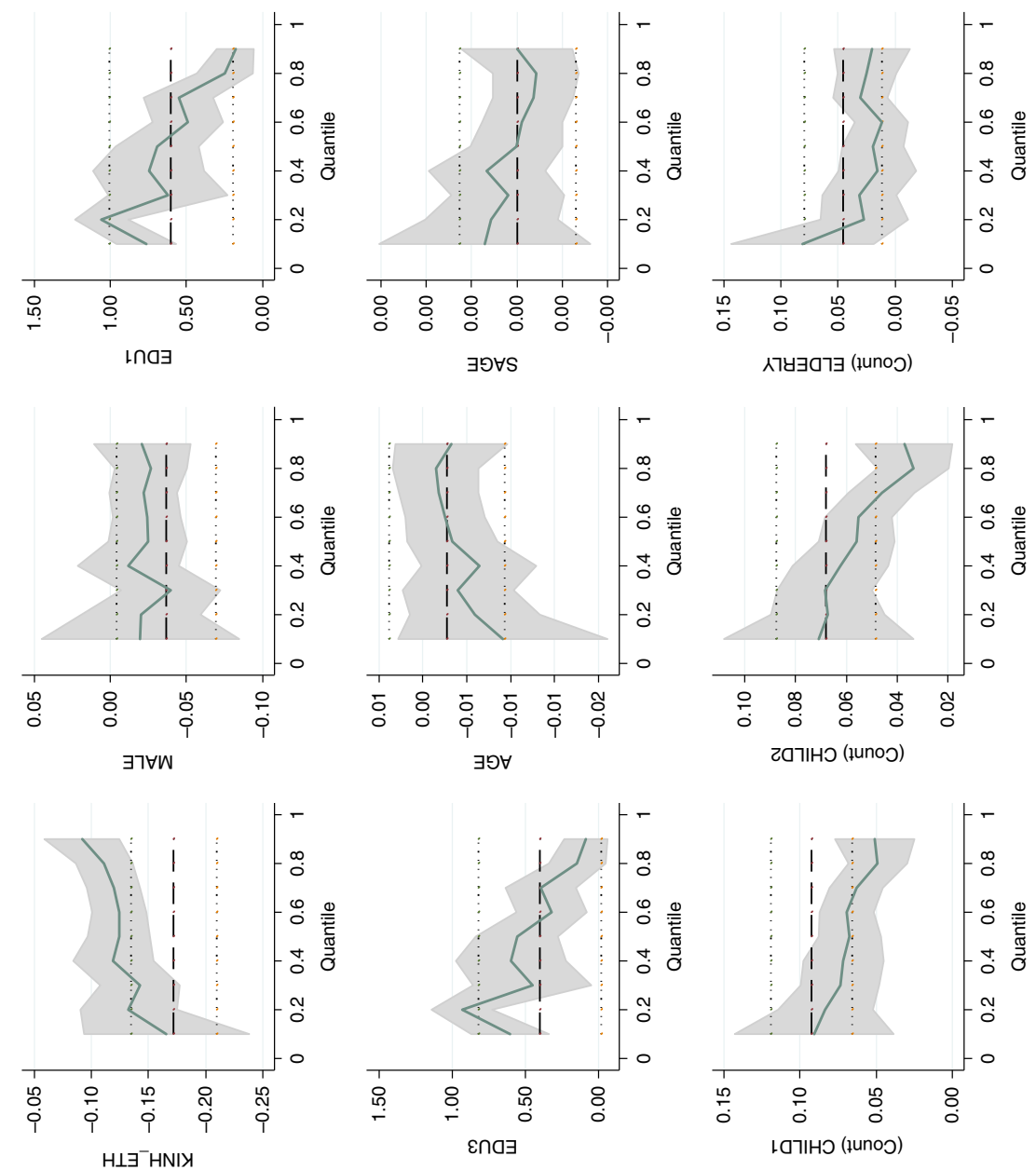

Figure 5.

Ordinary least squares regression and quantile regression estimates for Vietnamese
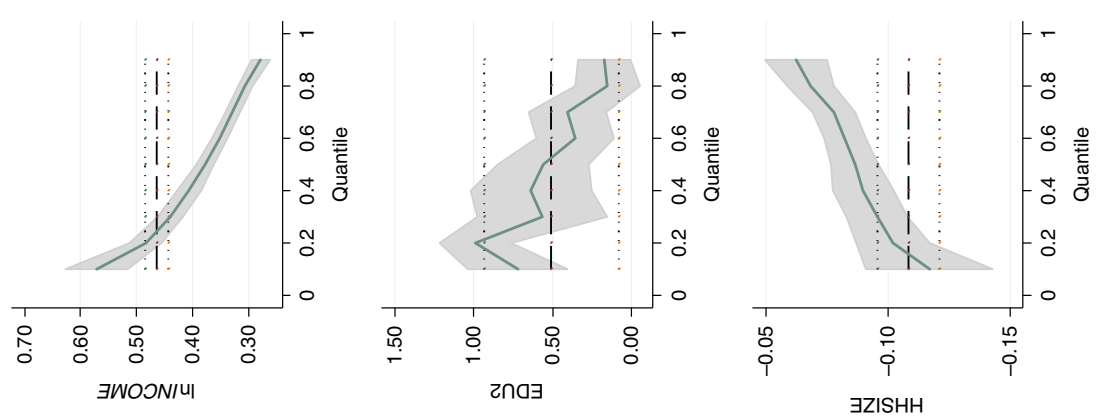

household saving rate in rural areas 
with low (i.e. negative) saving rates have a higher MPS than households with high saving rates. A 1 per cent increase of household income tends to have a larger effect on the saving rates of households with low saving rates than on those of households with high saving rates. If economic growth were equally spread over all households, we could therefore expect that the saving rates of households in the lower quantiles will increase faster than those of households in the higher quantiles, and hence that the inequality in Vietnamese household saving rates will decrease over time. The decline of the MPS happens for the sample as a whole as well as for urban and rural households separately. These declines are rather impressive and illustrated in the first scatterplots of Figures 3-5.

As far as household size is concerned, we find that it has a significant negative effect on the household saving rate for both the OLS and the quantile regression approach. It means that households with more members would consume more and therefore lower their saving rate. Our results are in line with the empirical finding that large households tend to have both lower saving levels (Abdelkhalek et al., 2010) and lower saving rates. The effect decreases in magnitude as the saving quantile increases. It exists for urban households as well as for rural ones.

Household living area. According to H1, we expect that rural households have higher saving rates than urban households, ceteris paribus. The results of Table II seem to confirm our expectation. In both regression approaches, the negative sign of the coefficient of the $U R B A N$ dummy means that saving rates of rural households are significantly higher than those of urban households, with other conditions remaining the same. This indicates that rural households have stronger saving motives than urban households. Our results are consistent with numerous preceding empirical studies (Akhtar, 1987; Bautista and Lamberte, 1990; Duesenberry, 1949; Friedman, 1957; Nalin, 2013; Pan, 2016; Qian, 1988; Bebczuk et al., 2015).

In fact, when we run the regressions for urban and rural households separately, we find that the MPS of rural households is higher than that of urban households. Additionally, the quantile regression results for the whole sample reveal that the MPS gap between rural and urban households is larger at low quantiles than at high quantiles, ceteris paribus. Hence, the effect of urbanisation appears to be stronger at lower quantiles of the saving rate distribution. Moreover, at high quantiles, the quantile regression results differ significantly from the OLS regression results (Figure 3).

Gender of the household head. With regard to the effect of the gender of the household head on household saving rates, we find there is not much evidence for a significant difference between male and female household heads. Hence, there is little support for $H 2$. This holds true for the whole sample as well as for urban and rural households. Our results are consistent with the findings of Gries and Dung (2014) for rural Vietnam.

Educational levels of the household head. As we pointed out above, the effect of the educational level of the household head on household saving behaviour is complex. Nevertheless, as we explained in $H 3$, we expect that household heads with a low educational level have higher saving rates due to their stronger saving motives. Results in Table II show that our expectation is confirmed by both regression approaches. The positive signs of the coefficients of the three educational dummies in all quantile regressions show that household heads with the highest educational level, the reference group, have the lowest saving rates. The magnitudes of the coefficients suggest that household heads with the lowest educational level have the highest saving rates and that increasing the levels of education tend to be associated with lower saving rates if other variables are controlled for. The results also indicate that this saving rate gap associated with the educational level of household heads decreases as the quantiles increase, except for the lowest quantile. And in some quantiles, the gaps are insignificant. 
JABES

27,2

188

What exactly explains the negative effect of the educational level of the household head on the saving rate of Vietnamese households is an open question which deserves to be explored further. Tran (2015) found that in Vietnam well-educated people often have high and stable incomes. As suggested by the permanent income hypothesis (Friedman, 1957), they would consume more and save less than those who have less stable incomes, ceteris paribus.

Looking at the results for urban and rural households separately, we find that the influence of the educational level of the household head on household saving rates is consistent in both cases. Nevertheless, according to the quantile regressions, the effect is larger for rural than for urban households. Additionally, within the group of urban households, only the coefficients of the low educational level dummy are significant. By contrast, within the group of rural households, all educational level dummies seem to have a significant effect on household saving behaviour.

Ethnicity of the household head. In accordance with our expectation expressed in $H 4$, we find that for the whole sample and both regression approaches, households with a Kinh household head tend to have lower saving rates than other households (Table II). In Figure 3 we notice that the solid curve representing the quantile regression estimates of the coefficient of the KINH_ETH dummy lies above and is mostly significantly different from the dashed line representing the OLS estimate of the coefficient. The plot shows that the saving rate gap which is associated to ethnicity declines from -0.131 at the lowest quantile to -0.077 at the highest quantile.

The effects of ethnicity on the household saving rates of urban and rural households are heterogeneous. In the case of urban households, this covariate has a significant effect for the quantiles which are above the median; in the case of rural households, the effect is significant for all quantiles. Therefore, we conclude that households with minor-ethnicity head would have stronger saving motive.

Children and elderly members. Last but least we consider the effect of children and elderly members on household saving rate. H5 stated that we expect children and elderly members to have a positive effect on household saving rates. Nevertheless, we also pointed out that the effect is complex. Our findings for the whole sample and for both urban and rural households show that Vietnamese households with more children and elderly members tend to have higher saving rates. This is consistent with the results of Minh et al. (2013) for Vietnam, of Curtis et al. (2015) for China and of Akhtar (1987) for Pakistan. According to the quantile regressions, the effect seems stronger for households with a low saving rate than for those with a high saving rate. The positive effect of children and elderly members on household saving rates suggests that in low and middle income countries they should be treated as part of the labour force of households, whereas in high income countries they are dependent members.

\section{Robustness analysis}

In this section, we explore the robustness of the quantile regression results for the whole sample of Vietnam by performing three additional analyses. The results for the quantiles $0.3,0.5$ and 0.8 are reported in Table III.

First, we use the number of years of schooling of the household head as an alternative for the four educational levels. The results obtained from Model 2 indicate that as the number of years of schooling increases, the saving rate tends to decrease. This coincides with our finding in the previous section.

Second, we define household dependency as the household size minus the household labourers, rather than as the sum of the number of children and elderly members. The results for Model 3 show that there is a negative relationship between household 


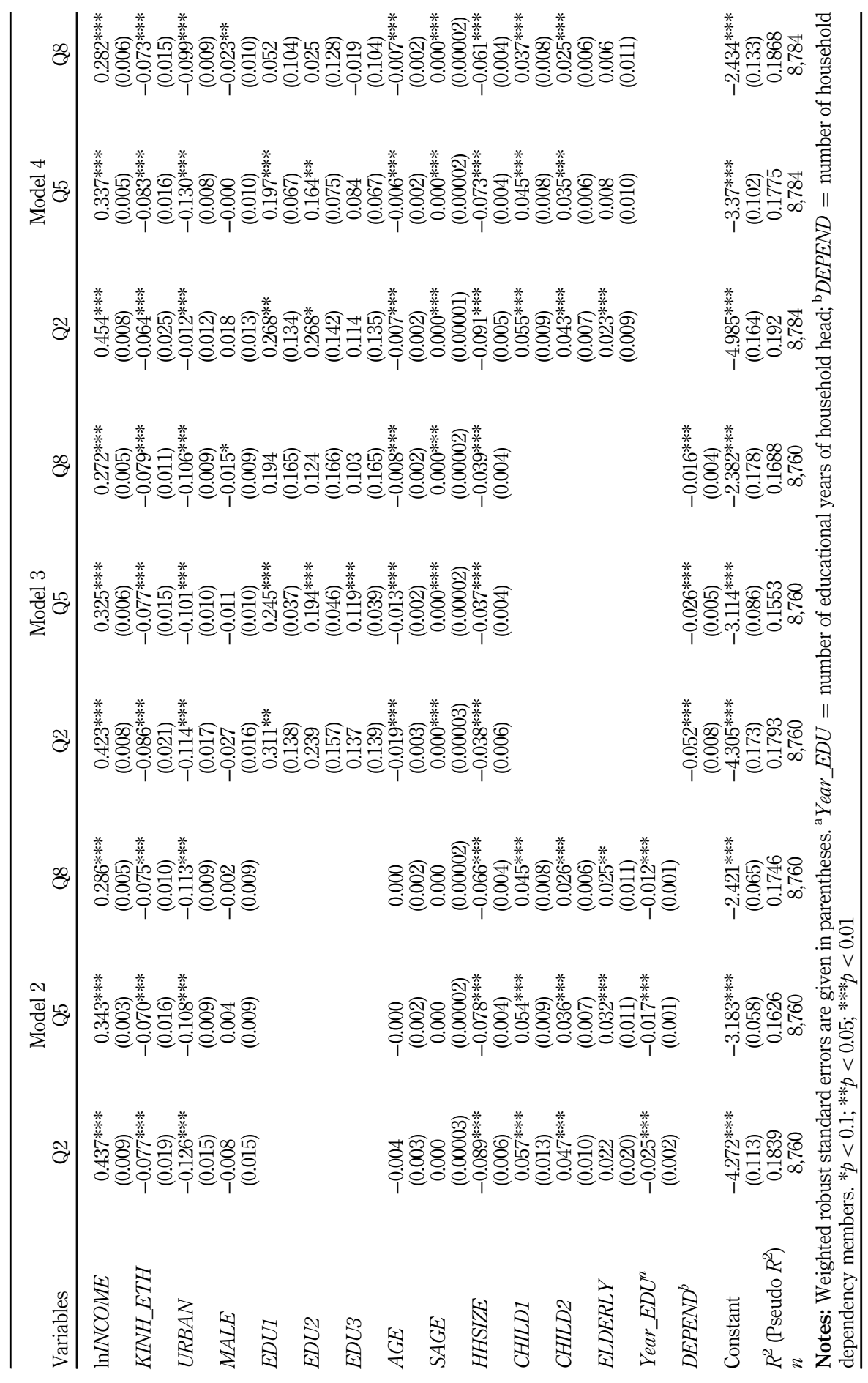

Applying quantile regression

189

Table III.

Robustness checks for the results of the quantile regression approach 
JABES

27,2

190

dependency and the saving rate. Again, this is consistent with what we found by defining dependency in terms of the number of children and elderly members.

Last, we use the data set VHLSS 2012 to test the robustness of our results. As presented in Model 4, the results of the two analyses are very similar. A suggestion for future research would be to redo the analysis with more recent data, such as VHLSS 2014 and 2016, in order to ensure that the results are not out-of-date.

\section{Conclusion}

In this paper, we considered the effects of household characteristics on the household saving rates by means of data from VHLSS 2010. In order to take into account the possible heterogeneity of household saving propensities, we applied quantile regression as an alternative for OLS regression. The most important result from the quantile regression approach is that many household characteristics appear to have stronger effects on the saving rate at low quantiles. The main conclusions we obtained from the OLS and quantile regressions can be summarised as follows.

First, in line with economic theory, we found that higher incomes induce higher saving rates. In addition, households in low quantiles of the household saving rate distribution have higher marginal propensities to save than households in high quantiles. This holds for both urban and rural households.

Second, consistent with previous empirical studies, we found that the saving behaviours of urban and rural households are heterogeneous. Particularly, the MPS of rural households rural is higher than that of urban households. This may be due to the fact that household incomes in rural areas are often more variable or unstable than those in urban areas. Additionally, the quantile regressions indicate that the effect of urbanisation on households with a low saving rate is higher than that on households with a high saving rate.

Third, the gender of the household head does not seem to be a crucial factor in the saving behaviour of Vietnamese households, especially for urban households.

Fourth, the ethnic background of the household head is an important determinant of saving rates for rural households. The influence is more pronounced for households with a low saving rate than for households with a high saving rate. Ethnicity is less crucial for urban areas.

Fifth, the educational level of the household head is also an important factor for household saving behaviour. We found that households with a low educational level household head tend to have higher saving rates than households with a high educational level household head. The effect appears to be stronger at low quantiles of the household saving rate distribution than at high quantiles.

Last but not least, our empirical evidence revealed that children and elderly members have a positive effect on household saving rates. This suggests they should be treated as part of the household labour force rather than as household dependency. The effect of children is more important than that of the elderly. The effects are somewhat different for urban and rural households.

\section{Notes}

1. Table AI provides more details on the mean and the standard deviation of the saving rate and of a selected number of covariates in the ten deciles of the saving rate distribution.

2. In our data, the mean of household saving levels is $12,803.69$ (VND 1,000) and that of household income levels 73,373.17 (VND 1,000).

3. The results for urban and rural households separately are available upon request from the authors. 


\section{References}

Abdelkhalek, T., Arestoff, F., Freitas, N.E.M.D. and Mage, S. (2010), "A microeconometric analysis of household savings determinants in Morocco", African Review of Money Finance and Banking, pp. 7-27.

Aizenman, J., Cavallo, E. and Noy, I. (2015), "Precautionary strategies and household saving", Open Economies Review, Vol. 26 No. 5, pp. 911-939.

Akhtar, S. (1987), "Dependency, urbanization, education and household savings: some preliminary evidence from Pakistan”, Saving and Development, Vol. 11 No. 4, pp. 337-353.

Aron, I.N. and Mihaescu, C. (2014), "Modelling the impact of economic, demographic and social determinants on household saving rate in the former socialist countries (Central and Eastern Europe)", Procedia Economics and Finance, Vol. 10, pp. 104-113.

Banerjee, A., Meng, X. and Qian, N. (2010), "The life cycle model and household savings: micro evidence from urban China”, unpublished working paper, Yale University, New Haven, CT.

Bautista, R.M. and Lamberte, M. (1990), "Comparative saving behavior of rural and urban households in the Philippines", Journal of Philippines Development, Vol. 17 No. 2, pp. 149-181.

Bebczuk, R., Gasparini, L., Garbero, N. and Amendolaggine, J. (2015), "Understanding the determinants of household saving: micro evidence for Latin America", Technical Report, CEDLAS, Universidad Nacional de La Plata/IDB, La Plata.

Bersales, L.G.S. and Mapa, D. (2006), "Patterns and determinants of household saving in the Philippines", Technical Report, USAID/Philippines OEDG, Makati City.

Borgo, M.D. (2019), "Ethnic and racial disparities in saving behavior", Journal of Economic Inequality, Vol. 17 No. 2, pp. 253-283.

Burney, N.A. and Khan, A.H. (1992), "Socio-economic characteristics and household savings: an analysis of the households' saving behavior in Pakistan”, Pakistan Development Review, Vol. 31 No. 1, pp. 31-48.

Charron-Chénier, R., Fink, J.J. and Keister, L.A. (2016), "Race and consumption: black and white disparities in household spending", Sociology of Race and Ethnicity, Vol. 3 No. 1, pp. 50-67.

Curtis, C.C., Lugauer, S. and Mark, N.C. (2015), "Demographic patterns and household saving in China", American Economic Journal: Macroeconomics, Vol. 7 No. 2, pp. 58-94.

Deaton, A. and Paxson, C. (2000), "Growth and saving among individuals and households", Review of Economics and Statistics, Vol. 82 No. 2, pp. 212-225.

Duesenberry, J.S. (1949), Income, Saving, and the Theory of Consumer Behavior, Harvard University Press, Cambridge, MA.

Fisher, P.J. (2010), "Gender differences in personal saving behaviors", Journal of Financial Counseling and Planning, Vol. 21 No. 1, pp. 14-24.

Friedman, M. (1957), A Theory of the Consumption Function, Princeton University Press, Princeton, NJ.

Goldberger, A.S. (1973), "Dependency rates and savings rates: further comment”, American Economic Review, Vol. 63 No. 1, pp. 232-233.

Gries, T. and Dung, H.V. (2014), "Household savings and productive capital formation in rural Vietnam: insurance vs social network", Modern Economy, Vol. 5 No. 8, pp. 878-894.

Ha, V.D., Phan, D.N. and Gries, T. (2015), "Short-term precaution, insurance, and saving mechanisms in rural Vietnam", Journal of Southeast Asian Economics, Vol. 32 No. 3, pp. 319-339.

Harris, M.N., Loundes, J. and Webster, E. (2002), "Determinants of household saving in Australia", Economic Record, Vol. 78 No. 241, pp. 207-223.

Horioka, C.Y. and Wan, J. (2007), "The determinants of household saving in China: a dynamic panel analysis of provincial data", Journal of Money, Credit and Banking, Vol. 39 No. 8, pp. 2077-2096.

Horioka, C.Y. and Watanabe, W. (1997), "Why do people save? A micro analysis of motives for household saving in Japan", Economic Journal, Vol. 107 No. 442, pp. 537-552.

Kelley, A.C. (1980), "Interactions of economic and demographic household behavior", in Easterlin, R.A. (Ed.), Population and Economic Change in Developing Countries, University of Chicago Press, Chicago, IL, pp. 403-470. 
JABES

27,2

192

Keynes, J.M. (1936), The General Theory of Employment, Interest and Money, Macmillan, London.

Khan, A.H., Hasan, L. and Malik, A. (1992), "Dependency ratio, foreign capital inflows and the rate of savings in Pakistan”, Pakistan Development Review, Vol. 31 No. 4, pp. 843-856.

Klein, L.R. (1951), "Estimating patterns of savings behavior from sample survey sata", Econometrica, Vol. 19 No. 4, pp. 438-454.

Koenker, R. and Bassett, G. (1978), "Regression quantiles”, Econometrica, Vol. 46 No. 1, pp. 33-50.

Loayza, N., Schmidt-Hebbel, K. and Serven, L. (2000), "Saving in developing countries: an overview", The World Bank Economic Review, Vol. 14 No. 3, pp. 393-414.

Martins, P.S. and Pereira, P.T. (2004), "Does education reduce wage inequality? Quantile regression evidence from 16 countries", Labour Economics, Vol. 11 No. 3, pp. 355-371.

Melly, B. (2005), "Public-private sector wage differentials in Germany: evidence from quantile regression", Empirical Economics, Vol. 30 No. 2, pp. 505-520.

Minh, N.T., Nhat, N.H., Anh, T.T., Duc, P.M. and Son, L.T. (2013), "Demographics and saving behavior of households in rural areas of Vietnam: an empirical analysis", Journal of Economics and Development, Vol. 15 No. 2, pp. 5-18.

Modigliani, F. and Brumberg, R. (1954), "Utility analysis and the consumption function: an interpretation of cross-section data", in Kurihara, K.K. (Ed.), Post Keynesian Economics, Rutgers University Press, New Brunswick, NJ, pp. 388-436.

Morisset, J. and Revoredo, C. (1995), "Savings and education: a life-cycle model applied to a panel of 74 countries”, Policy Research Working Paper No. 1504, World Bank, Washington, DC.

Nalin, H.T. (2013), "Determinants of household saving and portfolio choice behavior in Turkey", Acta Oeconomica, Vol. 63 No. 3, pp. 309-331.

Newman, C., Tarp, F. and Van den Broeck, K. (2014), "Social capital, network effects and savings in rural Vietnam", Review of Income and Wealth, Vol. 60 No. 1, pp. 79-99.

Newman, C., Tarp, F., Van den Broeck, K., Quang, C.T. and Khai, L.D. (2008), "Household savings in Vietnam: insights from a 2006 rural household survey", Vietnam Economic Management Review, Vol. 3 No. 1, pp. 34-40.

Pan, Y. (2016), "Understanding the rural and urban household saving rise in China”, Regional Science and Urban Economics, Vol. 56, pp. 46-59.

Qian, Y. (1988), "Urban and rural household saving in China”, Staff Papers (International Monetary Fund), Vol. 35 No. 4, pp. 592-627.

Rehman, H.u., Bashir, F. and Faridi, M.Z. (2011), "Saving behavior among different income groups in Pakistan: a micro study", International Journal of Humanities and Social Science, Vol. 1 No. 10, pp. 268-277.

Schunk, D. (2009), "What determines household saving behavior? An examination of saving motives and saving decisions", Journal of Economics and Statistics, Vol. 229 No. 4, pp. 467-491.

Sepehri, A. and Akram-Lodhi, A. (2005), "Transition, savings and growth in Vietnam: a three-gap analysis", Journal of International Development, Vol. 17 No. 4, pp. 553-574.

Szopinski, T. (2017), "The determinants of household savings in Poland", Acta Scientiarum Polonorum, Oeconomia, Vol. 16 No. 2, pp. 117-125.

Tran, T.T.A. (2015), "A quantile regression decomposition of urban-rural wage gap in Vietnam", Vietnam Economics and Development, Vol. 219 No. 9, pp. 20-29.

Warren, T., Rowlingson, K. and Whyley, C. (2001), "Female finances: gender wage gaps and gender asset gaps", Employment and Society, Vol. 15 No. 3, pp. 465-488.

\section{Corresponding author}

Guido Erreygers can be contacted at: guido.erreygers@uantwerpen.be 
Table AI. Mean and standard deviation in the ten deciles of the saving rate distribution 